\title{
Opinion
}

\section{The wisdom and eudaimonia of Paediatrics: An interview with Professor George P. Chrousos, Professor of Paediatrics and Endocrinology at the University of Athens, Greece}

\author{
IOANNIS N. MAMMAS ${ }^{1-3}$, MARIA THEODORIDOU ${ }^{2}$ and DEMETRIOS A. SPANDIDOS ${ }^{1}$ \\ ${ }^{1}$ Laboratory of Clinical Virology, School of Medicine, University of Crete, 71003 Heraklion; ${ }^{2}$ First Department of Paediatrics, \\ University of Athens School of Medicine, 11527 Athens; ${ }^{3}$ Paediatric Clinic, Aliveri, 34500 Island of Euboea, Greece
}

Received July 22, 2019; Accepted August 26, 2019

DOI: $10.3892 /$ etm.2019.7945

\begin{abstract}
Professor George P. Chrousos, Professor Emeritus of Paediatrics and Endocrinology at the University of Athens School of Medicine, in Athens, Greece, is the most distinguished Professor of Paediatrics in the modern history of Hellenic Paediatrics and among the 100 most prominent clinical investigators worldwide. According to Professor Chrousos, viruses frequently interact with the host endocrine signaling pathways, while stress triggers acutely an early inflammatory response termed 'neurogenic inflammation'. Soon after, however, stress suppresses innate immunity and causes a shift from T-helper 1- to T-helper 2- driven immunity. The natural history of the response to a viral infection is for immune and stress changes to take place in a highly coordinated process that results in the full return to the basal health state. He believes that over the past decades, our armamentarium against viruses has increased significantly as novel anti-viral agents, monoclonal antibodies and vaccines, have been and are continually being developed. Professor Chrousos declares that Paediatrics is a very broad scientific field, where paediatric trainees have many avenues to follow beyond clinical practice and into basic, preclinical, translational, clinical, applied, or epidemiologic research. He supports that researching and producing new knowledge to the benefit of humanity is a product of practicing Aristotle's ancient Greek virtues and a worthy cause of life's meaning. He completes our interview calling young paediatricians to 'listen to their minds and hearts' to select a life course that would lead them to acquire personal wisdom and eudaimonia.
\end{abstract}

Correspondence to: Professor Demetrios A. Spandidos, Laboratory of Clinical Virology, School of Medicine, University of Crete, 71003 Heraklion, Greece

E-mail: spandidos@spandidos.gr

Key words: George P. Chrousos, Paediatrics, Paediatric Endocrinology, University of Athens, medical education, Paediatric Virology

\section{Contents}

1. Introduction

2. Questions and Answers

\section{Introduction}

Born in Patras, Greece, in 1951, Professor George P. Chrousos (Fig. 1), Professor Emeritus of Paediatrics and Endocrinology at the University of Athens School of Medicine in Athens, Greece, studied Medicine at the University of Athens School of Medicine. During the period 2000 to 2018, he served as Chairman of the First Department of Paediatrics of the University of Athens at the 'Aghia Sophia' Children's Hospital in Athens, Greece, historically the first paediatric department founded in Greece. He has also been Senior Investigator and Director of the Paediatric Endocrinology Section and Training Programme, and Chief of the Paediatric and Reproductive Endocrinology Branch of the National Institute of Child Health and Human Development (NICHD) at the National Institutes of Health (NIH) and Professor of Paediatrics, Physiology and Biophysics at Georgetown University Medical School in Washington, DC, USA. He currently holds the UNESCO Chair on Adolescent Health Care at the University of Athens and he is an Affiliated Investigator at the Biomedical Research Foundation of the Academy of Athens in Athens (Greece).

Professor Chrousos's research has focused on the hypothalamic-pituitary-adrenal (HPA) axis and the neuroendocrine alterations associated with mood disorders, sleep, pain perception and immune function. His clinical and laboratory contribution is recognized worldwide for its extensive and highly original work on the glucocorticoid signalling system, diseases of the HPA axis, such as Cushing's syndrome, Addison's disease and congenital adrenal hyperplasia, and the physiologic and molecular mechanisms of stress. Early in his career, Professor Chrousos described in the Journal of Clinical Investigation the glucocorticoid resistance syndrome, a rare but unique and interesting genetic disease of the glucocorticoid receptor that causes hypertension and hyperandrogenism in children and adults. Subsequently, Professor Chrousos contributed the majority of the international original publications on this syndrome, which 
has served as a highly informative model for the study of the physiologic functions of these key steroid hormones that regulate the homeostasis of the organism and are critical for its survival.

Professor Chrousos has contributed immensely to the biomedical literature and his work has provided new insight into a spectrum of clinical conditions and disorders that transcend the limits of classical Paediatrics and Endocrinology, such as pregnancy, human development, surgical stress, sleep and septic shock, as well as chronic complex disorders, such as depression, eating disorders and autoimmune inflammatory diseases. $\mathrm{He}$ has an outstanding record of more than 1,500 scientific articles, and has also edited 29 books, including 2 popular electronic volumes and 2 encyclopaedias; to date, his work has been cited in more than 143,000 scientific articles; some selected titles of his publications are provided in the reference section (1-12).

Professor Chrousos is one of the 100 most cited scientists internationally (Institute of Scientific Information, ISI highly cited), included not only in the list of Clinical Medicine, but also in that of Biology and Biochemistry, and the highest cited clinical paediatrician or endocrinologist worldwide. Clinical Medicine includes all subspecialties of Internal Medicine, Surgery and Laboratory Medicine. His published work also has an extremely high impact factor of over 5,500 and an h-index of over 183. Professor Chrousos has published his work in journals of the highest calibre, such as the New England Journal of Medicine, in which he has a record of 13 full publications, the Journal of Clinical Investigation, the Annals of Internal Medicine, PNAS, Science and Nature.

Without any doubt, Professor Chrousos is the most distinguished Professor of Paediatrics in the modern history of Hellenic Paediatrics with a worldwide reputation and acceptance by the international medical community. Professor Chrousos will chair the '5th workshop on Paediatric Virology', which will be held in Sparta, Greece on October 12th, 2019, and his plenary lecture will focus on 'viral infections and stress'. In the context of the '5th Workshop on Paediatric Virology', Professor Chrousos will receive the '2019 George N. Papanicolaou Humanitarian Award' for his outstanding scientific contribution to the wealth of humanity. This award represents the highest honour awarded by the Paediatric Virology Study Group (PVSG).

\section{Questions and Answers}

Question: Viruses and human homeostasis; viruses interact with host endocrine system and alter different host endocrine signalling pathways. What are the most common endocrine manifestations in children with a viral infection?

Answer: True, viruses frequently interact with the host endocrine signalling pathways. We have concrete evidence for some viruses. For instance, HIV-1 has two accessory proteins, Vpr and Tat, which interact with the glucocorticoid and PPAR- $\gamma$ signalling pathways, causing respectively, glucocorticoid hypersensitivity and PPAR $-\gamma$ resistance. The former participates in the immunosuppression of the host by HIV-1, while the latter in the insulin resistance and lipodystrophy of the infected individual. We have other examples in Nature, such as the obesity of chicken infected with an adenovirus or the still unidentified virus or viruses responsible for the rare transient glucocorticoid hypersensitivity syndrome. We are

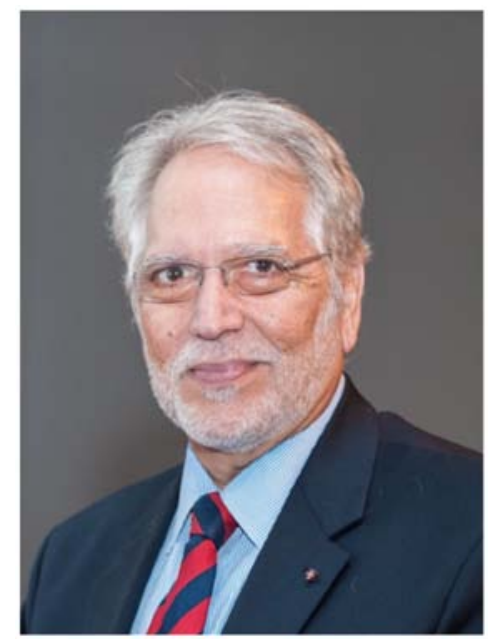

Figure 1. Professor George P. Chrousos, Professor Emeritus of Paediatrics and Endocrinology at the University of Athens School of Medicine and Chair of the '5th workshop on Paediatric Virology', Sparta, Greece, October 12, 2019.

still cognizant of the very tip of the iceberg regarding viral elements interfering with our signalling systems.

Question: How stress is involved in the immune response of a child with a viral infection?

Answer: Generally, stress triggers acutely an early inflammatory response termed 'neurogenic inflammation'. Soon after, however, stress suppresses innate immunity and causes a shift from T-helper 1- to T-helper 2- driven immunity. Recently, evidence was reported for an analogous effect on T-helper 17- and T-reg- driven immunity. The catecholamines norepinephrine and epinephrine and the glucocorticoids represent key hormones involved in the regulation of immunity and inflammation. A child with a viral infection will have an activated sickness syndrome, via the classic pro-inflammatory cytokines TNF- $\alpha$, interleukin-1, intereukin- 6 , etc., followed by an activated stress syndrome via the autonomic nervous system and the hypothalamic-pituitary-adrenal axis. The natural history of the response to a viral infection is for immune and stress changes to take place in a highly coordinated process that results in full return to the basal health state.

Question: A 5-month old infant with mild RSV-positive bronchiolitis attends the Paediatric Accident and Emergency (A\&E) Department; parents are anxious and seek antibiotics. In this case, how parental stress can be managed?

Answer: It is well known that antibiotics do not work with viruses. RSV-positive bronchiolitis is a common disorder that can be managed conservatively. Of course, if the severity is excessive and if we suspect a bacterial co-morbid infection, appropriate antibiotics should be given.

Question: Adenovirus-36 has been associated with human obesity, while several other viruses have also been studied for their possible causative interactions in type- 1 diabetes. What is the potential role of viral infections in the pathogenesis of type-1 diabetes in childhood?

Answer: Indeed, adenovirus-36 has been implicated in human obesity. The findings are still controversial though and we 
still do not know how this virus and its products interact with the human genome. This is a fascinating research project to undertake. Coxsackie viruses and enteroviruses have been implicated in the aetiology of diabetes mellitus type 1, perhaps as a result of molecular mimicry.

Question: Over the past years, research on paediatric viral infections has increasingly expanded into emerging new infections, new anti-virals and vaccines. According to your experience, what are the most significant advances in Paediatric Infectious Diseases (PID) over the past years?

Answer: Our armamentarium against viruses has increased significantly in the last decades. Novel anti-viral agents, monoclonal antibodies, and vaccines, have been and are continually being developed. The field of PID has benefitted greatly from these advances.

Question: In 2015, we proposed Paediatric Virology as a separate paediatric subspecialty candidate. How possible do you consider the implementation of a Paediatric Virology subspecialty programme focusing on paediatric viral infectious diseases into paediatric postgraduate education in the next years?

Answer: I think that Paediatric Virology as a knowledge field can definitely stand alone. Up to date, PID have Paediatric Virology as an integrated field, along with Bacteriology, Parasitology, study of fungal diseases, etc. However, due to the expected expansion of new knowledge on the field of neonatal and paediatric viral infections in the near future, Paediatric Virology can be considered carefully as an excellent candidate of a new paediatric subspecialisation. I believe that in this direction this very interesting and creative interaction between the University of Athens and the University of Crete Schools of Medicine could be the basis of the launching of a subspecialty programme on Paediatric Virology in the near future.

Question: The current financial crisis in Greece has led to the 'brain drain' of a great number of well-educated and talented scientists, including paediatric health professionals. In the future, how can this be changed?

Answer: We have lost a very large number of physicians and scientists that work with children and adolescents to other countries. Most of these professionals really did not have a choice but to leave. As a country, we have done little to keep them here or to bring them back if they have gone. The country must get serious about creating appropriate structures and increase funding for education, science and research. Our country is going the sorry way of Maghrebization.

Question: The achievements of the Greek immigrants have, though, a positive influence on our country. Our greatest poets, such as Dionysios Solomos, Andreas Kalvos and Constantine Cavafy, had a foreign citizenship. When we are talking about Greek musicians, we refer to Mitropoulos, Maria Kallas, Xenakis. Our important philosophers and artists lived in foreign countries. And in sports, in 2004, the Greek football team, which won the European championship consisted of footballers playing football outside Greece. We would like your comment on this. Answer: We are a talented people, with education as a very worthy ideal deeply inculcated in our conscience. We should take advantage, in a good sense, of the Greek diaspora with its many successful people of Greek descent, and we should try to send our youth to other countries for limited time periods to learn, improve themselves, and return to serve our society.

Questions: The Paediatric Virology Study Group (PVSG) has proposed you as the '2019 George N. Papanicolaou Humanitarian Award' recipient for your outstanding scientific contribution to the wealth of humanity. We would appreciate if we could have your comment on the contribution of Dr George N. Papanicolaou (Kymi, Island Euboea, Greece, 1883 - Miami, Florida, USA, 1962) in Medicine.

Answer: Dr George N.Papanicolaou is clearly a great benefactor of humanity. The lives of millions of women have been saved by his famous Pap test. He introduced a new medical field, and his work not only helped with the prevention of uterine cervical cancer, but also led to the discovery of the HPV vaccine that protects women and men from various cancers.

Question: But Dr George N. Papanicolaou did not manage to return home. You did it. How difficult was your return to Greece, indeed?

Answer: Dr George N. Papanicolaou wanted to return to his country; however, the conditions of the time did not allow it. He helped Greece from his position in America. For me, the difficulty at the beginning was the cultural shock. I found a different Greece when I came back after a quarter of a century. However, I met excellent people here who helped me adapt and who shared my educational and research philosophy. I have the feeling of satisfaction that I did as much as I could for Greece. I have not regretted it at all that I returned. I recommend return of all Greek scientists, but under conditions that would allow them to flourish.

Question: In your lectures you frequently refer to the ancient Greek philosopher Aristotle (Stagira, Chalkidiki, 384 BC-322 BC, Chalkida, Island of Euboea). We read in one of his quotes: 'Every art and every inquiry, and similarly every action and pursuit, is thought to aim at some good; and for this reason the good has rightly been declared to be that, at which all things should aim'. How significant is this really in science? Answer: Aristotle rightly believed that practicing the ancient virtues was the way to find eudaimonia. Researching and producing new knowledge for the benefit of humanity is, of course, a product of practicing the virtues and a worthy cause of life's meaning. I know that most scientific advances have sprung from basic research and, hence, I believe that all research, basic, preclinical, translational, clinical, applied, epidemiologic, etc., that contributes to the betterment of the human condition is applaudable.

Question: You are considered as the most distinguished Professor of Paediatrics in the modern history of Hellenic Paediatrics with a worldwide reputation and acceptance by our international medical community. What is your most valuable 'virtue/value' in your paediatric career?

Answer: This is a tough question. I have been a seeker of knowledge and wisdom. Also, I am a very curious person and I like children. When I made my decision to go into Medicine it was not only to serve my fellow man, but also to learn how humans think and feel. The development of a child is an amazing 
process. You cannot understand man if you cannot comprehend how she or he reached the adult stage. It has been a great, happy career. I have enjoyed learning and I have had a wonderful time caring for children and their parents.

Question: Hospital-based Medicine, academic teaching or basic research? Which one do you enjoy most?

Answer: All three I should say, although I feel I enjoy more being a scientist. Hospital-based Medicine brings us closer to severe disease, academic teaching is a great pleasure, as you transmit new knowledge to other people, students, colleagues, or even laymen, and basic research is the background of most major innovations.

Question: Paediatrics, Endocrinology or Paediatric Endocrinology? In which one do you consider that your contribution was the most significant?

Answer: Most of my research has been in Paediatric and Adult Endocrinology. I was trained in Paediatrics and, subsequently, in Endocrinology, Metabolism and Diabetes, and, finally, I founded the first Paediatric Endocrinology Training Programme at the National Institutes of Health, Bethesda, MD, USA. My contribution has been in the understanding of stress and stress-related disorders, which is pertinent to all human beings, of all ages, with foetal, early childhood (first 5 years of life) and adolescence being the most vulnerable. The work transcends the limits of Paediatrics and Medicine, involving practically all aspects of Medicine, Psychiatry, Psychology, Surgery and Laboratory Medicine.

Question: How paediatric clinical practice is expected to change in the following years?

Answer: The clinical practice of Paediatrics will include not only children, but also adolescents and young men and women. Beyond the traditional Paediatrics, as the Medicine of children and adolescents, developmental and behavioural Paediatrics will be part of the paediatric routine practice. The paediatrician will serve as a family physician.

Question: What would be your advice to junior paediatric trainees?

Answer: I would recommend some soul-searching first. What is it that they enjoy and what do they desire to adopt as a life purpose that gives them meaning? Do they want to serve youth by providing them first rate clinical care? Do they want to go beyond clinical practice and into research, and what kind of research? Basic, preclinical, translational, clinical, or epidemiologic? Those who want to go into research will require additional training in the context of a subspecialty or with a doctorate or a post-doctoral fellowship in various scientific fields. Paediatrics is a very broad field with many avenues to follow. Young paediatricians should listen to their minds and hearts to select a life course that would allow them to acquire personal wisdom and eudaimonia.

Question: Thank you for your wise, inspirational and educational answers. We really look forward to your chair-ship and your plenary lecture on 'viral infections and stress' at the '5th workshop on Paediatric Virology', which will take place in Sparta, Greece, on October 12th, 2019.

\section{Acknowledgements}

This article is published in the third supplement issue of the Experimental and Therapeutic Medicine, which is dedicated to Paediatric Virology. This edition is performed in the context of the '5th workshop on Paediatric Virology' (Sparta, Greece, October 12, 2019) organized by the Paediatric Virology Study Group (PVSG) and supported by the Laboratory of Clinical Virology, School of Medicine, University of Crete and the First Department of Paediatrics of the University of Athens School of Medicine. We would like to thank Professor George P. Chrousos for this educational and inspirational interview-style article. We would also like to thank all the members of the PVSG for their interesting questions to Professor Chrousos and their valuable comments.

\section{References}

1. Chrousos GP, Renquist D, Brandon D, Eil C, Pugeat M, Vigersky R, Cutler GB Jr, Loriaux DL and Lipsett MB: Glucocorticoid hormone resistance during primate evolution: Receptor-mediated mechanisms. Proc Natl Acad Sci USA 79: 2036-2040, 1982.

2. Chrousos GP, Vingerhoeds A, Brandon D, Eil C, Pugeat M DeVroede M, Loriaux DL and Lipsett MB: Primary cortisol resistance in man. A glucocorticoid receptor-mediated disease. J Clin Invest 69: 1261-1269, 1982.

3. Chrousos GP, Schulte HM, Oldfield EH, Gold PW, Cutler GB Jr and Loriaux DL: The corticotropin-releasing factor stimulation test. An aid in the evaluation of patients with Cushing's syndrome. N Engl J Med 310: 622-626, 1984.

4. Gold PW, Gwirtsman H, Avgerinos PC, Nieman LK, Gallucci WT, Kaye W, Jimerson D, Ebert M, Rittmaster R, Loriaux DL, et al: Abnormal hypothalamic-pituitary-adrenal function in anorexia nervosa. Pathophysiologic mechanisms in underweight and weight-corrected patients. N Engl J Med 314: 1335-1342, 1986.

5. Udelsman R, Ramp J, Gallucci WT, Gordon A, Lipford E, Norton JA, Loriaux DL and Chrousos GP: Adaptation during surgical stress. A reevaluation of the role of glucocorticoids. J Clin Invest 77: 1377-1381, 1986.

6. Luger A, Deuster PA, Kyle SB, Gallucci WT, Montgomery LC, Gold PW, Loriaux DL and Chrousos GP: Acute hypothalamic-pituitary-adrenal responses to the stress of treadmill exercise. Physiologic adaptations to physical training. N Engl J Med 316: 1309-1315, 1987.

7. Calogero A, Gallucci WT, Gold PW and Chrousos GP: Multiple feedback regulatory loops upon rat hypothalamic corticotropin-releasing hormone secretion. Potential clinical implications. J Clin Invest 82: 767-774, 1988.

8. Hurley D, Accilli D, Stratakis C, Karl M, Vamvakopoulos N, Rorer E, Constantine K, Taylor S and Chrousos GP: Mutation of the Glucocorticoid Receptor Gene in Familial Glucocortcoid Resistance. J Clin Invest 87: 680-686, 1991.

9. Karalis K, Sano H, Redwine J, Listwak S, Wilder RL and Chrousos GP: Autocrine or paracrine inflammatory actions of corticotropin-releasing hormone in vivo. Science 254: 421-423, 1991.

10. Vamvakopoulos NC and Chrousos GP: Evidence of direct estrogenic regulation of human corticotropin-releasing hormone gene expression. Potential implications for the sexual dimophism of the stress response and immune/inflammatory reaction. J Clin Invest 92: 1896-1902, 1993.

11. Tsigos C, Arai K, Hung W and Chrousos GP: Hereditary isolated glucocorticoid deficiency is associated with abnormalities of the adrenocorticotropin receptor gene. J Clin Invest 92: 2458-2461, 1993.

12. Magiakou MA, Mastorakos G, Oldfield EH, Gomez MT, Doppman JL, Cutler GB Jr, Nieman LK and Chrousos GP: Cushing's syndrome in children and adolescents. Presentation, diagnosis, and therapy. N Engl J Med 331: 629-636, 1994.

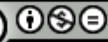

This work is licensed under a Creative Commons Attribution-NonCommercial-NoDerivatives 4.0 International (CC BY-NC-ND 4.0) License. 